\title{
SIFAT-SIFAT FUNGSI JARAK PADA MANIFOLD RIEMANNIAN
}

\author{
RIRI ALFAKHRIATI, JENIZON, HARIPAMYU \\ Jurusan Matematika, \\ Fakultas Matematika dan Ilmu Pengetahuan Alam, Universitas Andalas, \\ Kampus UNAND Limau Manis Padang, Indonesia. \\ email : ririalfakhriati123@gmail.com
}

\begin{abstract}
Abstrak. Manifold Riemannian merupakan manifold smooth yang dilengkapi dengan metrik Riemannian. Metrik Riemannian pada suatu manifold smooth $M$ adalah hasilkali dalam yang bersifat simetri, bilinier, dan definit positif pada setiap ruang singgung $T_{p} M$. Salah satu hal yang menarik dari manifold Riemannian adalah bahwa sebarang manifold Riemannian dapat ditinjau sebagai suatu ruang metrik dengan fungsi jarak yang didefinisikan pada manifold Riemannian. Pada penelitian ini, akan dikaji metrik Riemannian dan sifat-sifat fungsi jarak pada manifold Riemannian.
\end{abstract}

Kata Kunci: Manifold smooth, metrik Riemannian, manifold Riemannian, ruang metrik

\section{PENDAHULUAN}

Manifold Riemannian merupakan manifold smooth yang dilengkapi dengan suatu metrik Riemannian. Manifold adalah suatu ruang topologi yang secara lokal terlihat seperti ruang Euclidean. Persyaratan pertama untuk mentransfer ide dari kalkulus ke manifold adalah gagasan "smoothness" [5]. Dalam beberapa buku, istilah fungsi smooth adalah fungsi yang dapat diturunkan berkali-kali dinotasikan sebagai $C^{\infty}$ [6]. Salah satu gagasan yang diperlukan untuk memperluas pemahaman tentang penerapan manifold pada ruang $\mathbb{R}^{n}$ yang melibatkan kalkulus yaitu ide tentang manifold smooth. Metrik Riemannian pada dasarnya merupakan suatu hasilkali dalam pada setiap ruang singgung. Setiap manifold smooth memiliki metrik Riemannian. Pemilihan metrik Riemannian memungkinkan untuk mendefinisikan suatu konsep panjang dan jarak pada manifold smooth. Pada penelitian ini akan dikaji metrik Riemannian dan manifold Riemannian, serta dan sifat-sifat fungsi jarak pada manifold Riemannian [2].

\section{LANDASAN TEORI}

\subsection{Ruang Hasilkali Dalam}

Definisi 2.1. [1] Suatu hasilkali dalam pada sebuah ruang vektor riil $V$ adalah sebuah fungsi yang mengaitkan sepasang vektor $u$ dan $v$ di $V$ dengan bilangan riil $\langle u, v\rangle$ sedemikian sehingga untuk setiap $u, v$ dan $w$ di dalam $V$ dan untuk semua skalar $k$ memenuhi sifat : 
(1) $\langle u, v\rangle=\langle v, u\rangle$

(2) $\langle u+v, w\rangle=\langle u, w\rangle+\langle v, w\rangle$

(3) $\langle k u, v\rangle=k\langle u, v\rangle$

(4) $\langle v, v\rangle \geq 0$ dan $\langle v, v\rangle=0$ jika dan hanya jika $v=0$.

Ruang $(V,\langle\cdot, \cdot\rangle)$ disebut ruang hasilkali dalam riil.

Contoh 2.2. Ruang vektor $\mathbb{R}^{n}$ merupakan ruang hasilkali dalam dengan hasilkali dalam standar pada $\mathbb{R}^{n}$ didefinisikan oleh

$$
\langle x, y\rangle=x^{1} y^{1}+x^{2} y^{2}+x^{3} y^{3}+\cdots+x^{n} y^{n}
$$

untuk setiap $x, y \in \mathbb{R}^{n}$.

\subsection{Ruang Norm}

Definisi 2.3. [5] Misalkan $V$ suatu ruang vektor riil. Suatu norm pada $V$ adalah suatu fungsi $\|\cdot\|: V \longrightarrow \mathbb{R}$ yang memenuhi sifat :

(1) $\|x\| \geq 0$ untuk semua $x \in V$ dan $\|x\|=0$ jika dan hanya jika $x=0$

(2) $\|\alpha x\|=|\alpha|\|x\|$ untuk semua $\alpha \in \mathbb{R}$ dan $x \in V$

(3) $\|x+y\| \leq\|x\|+\|y\|$ untuk semua $x, y \in V$.

Pasangan $(V,\|\cdot\|)$ disebut ruang bernorm.

Contoh 2.4. Ruang vektor $\mathbb{R}^{n}$ merupakan suatu ruang norm dengan norm dari suatu vektor $x \in \mathbb{R}^{n}$ didefinisikan oleh $\|x\|=\left(\sum_{i=1}^{n}\left(x^{i}\right)^{2}\right)^{\frac{1}{2}}$ dan disebut norm $E u$ clidean.

\subsection{Ruang Metrik}

Definisi 2.5. [4] Misalkan $X$ suatu himpunan tak kosong. Suatu metrik pada $X$ adalah suatu fungsi $d: X \times X \longrightarrow \mathbb{R}$ yang mempunyai sifat sebagai berikut :

(1) $d(x, y) \geq 0$, untuk setiap $x, y \in X$ dan $d(x, y)=0$ jika dan hanya jika $x=y$

(2) $d(x, y)=d(y, x)$, untuk setiap $x, y \in X$

(3) $d(x, z) \leq d(x, y)+d(y, z)$, untuk setiap $x, y, z \in X$.

Pasangan $(X, d)$ disebut ruang metrik dimana $X$ adalah himpunan tak kosong dan $d$ adalah metrik pada $X$.

Contoh 2.6. Fungsi $d$ yang didefinisikan oleh

$$
d(x, y)=\|x-y\|=\left(\sum_{i=1}^{n}\left(x^{i}-y^{i}\right)^{2}\right)^{\frac{1}{2}}
$$

dimana $x, y \in \mathbb{R}^{n}$ merupakan suatu metrik pada $\mathbb{R}^{n}$ dan disebut metrik Euclidean.

Definisi 2.7. [5] Misalkan $(X, d)$ suatu ruang metrik, $x \in X$ dan $r$ suatu bilangan riil tak negatif. Suatu bola buka dengan pusat $x$ dan jari-jari $r$ adalah

$$
B(x, r)=\{y \in X: d(x, y)<r\} .
$$


142 Riri Alfakhriati dkk.

Suatu bola tutup dengan pusat $x$ dan jari-jari $r$ adalah

$$
\bar{B}(x, r)=\{y \in X: d(x, y) \leq r\} .
$$

Definisi 2.8. [5] Suatu himpunan bagian $U$ dari ruang metrik $X$ dikatakan buka pada $X$ jika untuk setiap $p \in U$ terdapat bola buka $B(p, r)$ dengan pusat $p$ dan jari-jari $r$ sedemikian sehingga berlaku $B(p, r) \subset U$.

\subsection{Ruang Topologi}

Definisi 2.9. [4] Suatu topologi pada himpunan $X$ adalah suatu koleksi $\mathcal{T}$ dari himpunan-himpunan bagian dari $X$ yang memenuhi:

(1) $\varnothing \in \mathcal{T}$ dan $X \in \mathcal{T}$

(2) Jika $U_{1}, U_{2}, \ldots, U_{n}$ elemen dari $\mathcal{T}$, maka irisan dari $U_{1} \cap U_{2} \cap \ldots \cap U_{n}$ juga elemen dari $\mathcal{T}$.

(3) Jika $\left(U_{\alpha}\right)_{\alpha \in A}$ dengan $A$ adalah himpunan indeks, sebarang koleksi dari elemen $\mathcal{T}$ maka $\bigcup_{\alpha \in A}\left(U_{\alpha}\right)$ (berhingga atau tak hingga) adalah elemen dari $\mathcal{T}$.

Suatu pasangan $(X, \mathcal{T})$ yang terdiri dari suatu himpunan $X$ dan suatu topologi $\mathcal{T}$ pada $X$ disebut ruang topologi.

Contoh 2.10. Koleksi dari himpunan-himpunan bagian buka dari $\mathbb{R}^{n}$ adalah suatu topologi pada $\mathbb{R}^{n}$ yang disebut topologi standar dari $\mathbb{R}^{n}$.

Definisi 2.11. [4] Misalkan $M$ dan $N$ suatu ruang topologi, maka $f: M \longrightarrow N$ dikatakan homeomorfisma jika $f$ pemetaan yang bijektif sedemikian sehingga $f$ dan $f^{-1}$ kontinu. Jika ada suatu homeomorfisma antara ruang topologi $M$ dan $N$, maka dapat dikatakan bahwa $M$ dan $N$ adalah homeomorfik.

Definisi 2.12. [4] Suatu ruang topologi $M$ dikatakan Euclidean lokal berdimensi $n$ apabila untuk setiap $x \in M$ terdapat lingkungan $U$ dari $x$ dengan $U \subseteq M$ yang homeomorfisma terhadap suatu himpunan bagian buka dari $\mathbb{R}^{n}$.

Definisi 2.13. [4] Suatu ruang topologi $(X, \mathcal{T})$ dikatakan ruang Hausdorff jika untuk setiap $x, y \in X$ dengan $x \neq y$ terdapat lingkungan $U$ dari $x$ dan $V$ dari $y$ yang memenuhi $U \cap V=\emptyset$.

Contoh 2.14. Ruang metrik $\left(\mathbb{R}^{n}, d\right)$ dengan $d$ didefinisikan pada Contoh 2.6 adalah ruang Hausdorff.

Definisi 2.15. [4] Misalkan $(X, \mathcal{T})$ ruang topologi. Suatu koleksi $\mathcal{B}$ dari himpunanhimpunan bagian buka dari $X$ disebut basis untuk topologi $\mathcal{T}$ jika untuk setiap himpunan bagian buka $U$ dari $X$ dan titik $p$ di $U$, maka terdapat suatu himpunan buka $B \in \mathcal{B}$ sedemikian sehingga $p \in B \subset U$. Hal ini juga dapat disebut $\mathcal{B}$ membangun topologi $\mathcal{T}$ atau $\mathcal{B}$ adalah suatu basis untuk ruang topologi $X$.

Definisi 2.16. [5] Suatu ruang topologi $X$ dikatakan second countable jika terdapat suatu countable basis pada topologi $X$.

Contoh 2.17. Ruang Euclidean $\mathbb{R}^{n}$ adalah second countable. 


\subsection{Manifold Smooth}

Definisi 2.18. [5] Misalkan $M$ suatu ruang topologi. M dikatakan manifold topologi berdimensi $n$ atau n-manifold topologi apabila memenuhi

(1) $M$ adalah ruang Hausdorff

(2) $M$ adalah second countable

(3) $M$ adalah Euclidean lokal berdimensi n, yaitu setiap titik di M memiliki lingkungan yang homeomorfik ke suatu sub himpunan buka di $\mathbb{R}^{n}$.

Contoh 2.19. Ruang Euclidean $\mathbb{R}^{n}$ adalah suatu $n$-manifold topologi.

Definisi 2.20. [5] Misalkan $U$ dan $V$ adalah himpunan-himpunan bagian buka dari ruang Euclidean $\mathbb{R}^{n}$ dan $\mathbb{R}^{m}$ secara berturut-turut. Suatu fungsi $F: U \longrightarrow V$ dikatakan smooth (atau $\boldsymbol{C}^{\infty}$ atau terdeferensial secara tak berhingga) jika untuk setiap komponen fungsinya memiliki turunan parsial kontinu dari semua orde (tingkat). Jika $F$ bijektif serta $F$ dan $F^{-1}$ smooth, maka $F$ disebut diffeomorfisma. Jika ada suatu diffeomorfisma antara $U$ dan $V$, maka dapat dikatakan bahwa $U$ dan $V$ adalah difeomorfik.

Suatu chart pada manifold topologi $M$ adalah suatu pasangan $(U, \varphi)$ dimana $U$ adalah himpunan bagian buka dari $M$ dan $\varphi: U \longrightarrow \hat{U}$ adalah suatu homeomorfisma dengan $\hat{U}=\varphi(U) \subseteq \mathbb{R}^{n}$. Untuk setiap titik $p \in U$, komponen fungsi $\left(x^{1}, \cdots, x^{n}\right)$ dari $\varphi$ yang didefinisikan $\varphi(p)=\left(x^{1}(p), \cdots, x^{n}(p)\right)$ dikatakan koordinat lokal atau koordinat lingkungan pada $U$. Jika $(U, \varphi),(V, \varphi)$ adalah dua chart yang memenuhi $U \cap V \neq \emptyset$, fungsi komposisi $\psi \circ \varphi^{-1}: \varphi(U \cap V) \longrightarrow \psi(U \cap V)$ dikatakan pemetaan transisi dari $\varphi$ ke $\psi$. ua chart $(U, \varphi),(V, \varphi)$ dikatakan smoothly compatible jika $U \cap V=\emptyset$ atau pemetaan transisi $\psi \circ \varphi^{-1}$ adalah suatu difeomorfisma. [5]

Definisi 2.21. [5] Misalkan $M$ suatu manifold topologi. Suatu atlas pada $M$ adalah suatu koleksi chart yang domain dari atlas menyelimuti $M$. Suatu atlas $\mathcal{A}$ dikatakan atlas smooth jika dua chart di $\mathcal{A}$ adalah smoothly compatible satu sama lain. Suatu struktur smooth pada $M$ adalah maksimal dari atlas smooth .

Definisi 2.22. [5] Suatu manifold smooth adalah pasangan $(M, \mathcal{A})$, dimana $M$ adalah suatu manifold topologi dan $\mathcal{A}$ adalah struktur smooth pada $M$.

Contoh 2.23. Ruang Euclidean $\mathbb{R}^{n}$ adalah manifold smooth berdimensi $n$ dengan struktur smooth yang ditentukan oleh atlas $\mathcal{A}$ yang terdiri dari chart tunggal $\left(\mathbb{R}^{n}, i d_{\mathbb{R}^{n}}\right)$.

Definisi 2.24. [5] Misalkan $M$ adalah manifold smooth dan $p \in M$. Suatu pemetaan linier $v: C^{\infty}(M) \longrightarrow \mathbb{R}$ disebut turunan pada p jika memenuhi

$$
v(f g)=f(p) v g+g(p) v g
$$

untuk semua $f, g \in C^{\infty}(M)$. 
144 Riri Alfakhriati dkk.

Himpunan dari semua turunan dari dari pemetaan $v$ pada $p$ disebut ruang singgung pada $M$ di titik $p$ yang dinotasikan $T_{p} M$. Anggota dari $T_{p} M$ disebut disebut vektor singgung pada $p$ yang dapat ditulis sebagai

$$
v=\left.\sum_{i=1}^{n} v^{i} \frac{\partial}{\partial x^{i}}\right|_{p}
$$

Vektor $\left.\frac{\partial}{\partial x^{i}}\right|_{p}$ dikatakan vektor koordinat pada $p$ yang berkaitan dengan sistem koordinat. Vektor koordinat $\left(\frac{\partial}{\partial x^{1}}, \cdots, \frac{\partial}{\partial x^{n}}\right)$ membentuk suatu basis untuk $T_{p} M[5]$.

Definisi 2.25. [6] Pemetaan $\gamma:(a, b) \longrightarrow \mathbb{R}^{n}$ disebut kurva di $\mathbb{R}^{n}$ yang dapat ditulis sebagai

$$
\gamma(t)=\left(\gamma^{1}(t), \cdots, \gamma^{n}(t)\right)
$$

dengan masing-masing $\gamma^{i}$ fungsi bernilai riil dan $t \in(a, b)$. Jika masing-masing $\gamma^{i}$ terdeferensial, maka kurva $\gamma$ disebut kurva smooth.

Definisi 2.26. [5] Misalkan $M$ suatu manifold smooth. Suatu kurva di $M$ adalah pemetaan kontinu $\gamma: J \longrightarrow M$ dimana $J$ adalah suatu interval dan $J \subset \mathbb{R}$.

Misalkan $M$ suatu manifold smooth. Jika $\gamma: J \longrightarrow M$ adalah suatu kurva smooth, maka untuk setiap $t \in J$ vektor laju dari $\gamma$ pada $t$ dinotasikan $\gamma^{\prime}(t)$ adalah vektor di $T_{\gamma(t)} M$. Vektor laju dari $\gamma$ pada $t_{0} \in J$ dapat ditulis:

$$
\gamma^{\prime}\left(t_{0}\right)=\frac{d \gamma}{d t}\left(t_{0}\right)
$$

dimana $\frac{d}{d t}$ adalah suatu basis koordinat standar di $T_{t_{0}} \mathbb{R}$. [5]

Definisi 2.27. [5] Misalkan diberikan suatu reparameterisasi $\tilde{\gamma}=\gamma \circ \varphi$ dari bagian kurva smooth $\gamma:[a, b] \longrightarrow M$ dimana $\varphi:[c, d] \longrightarrow[a, b]$ suatu diffeomorfisma, maka

$$
\tilde{\gamma}^{\prime}(t)=\gamma^{\prime}(\varphi(t)) \varphi^{\prime}(t)
$$

\section{PEMBAHASAN}

\subsection{Metrik Euclidean pada $\mathbb{R}^{n}$}

Definisi 3.1. [6] Suatu pemetaan $\varphi: \mathbb{R}^{n} \longrightarrow \mathbb{R}^{n}$ dikatakan isometri jika untuk setiap $x, y \in \mathbb{R}^{n}$, berlaku :

$$
\|\varphi(x)-\varphi(y)\|=\|x-y\|
$$

Definisi 3.2. [6] Suatu pemetaan linier $\varphi: \mathbb{R}^{n} \longrightarrow \mathbb{R}^{n}$ dikatakan ortogonal jika untuk setiap $x, y \in \mathbb{R}^{n}$ berlaku :

$$
\langle\varphi(x), \varphi(y)\rangle=\langle x, y\rangle .
$$

Proposisi 3.3. Sebarang pemetaan ortogonal adalah isometri. 
Bukti. Misalkan $\varphi: \mathbb{R}^{n} \longrightarrow \mathbb{R}^{n}$ suatu pemetaan ortogonal. Ambil $x, y \in \mathbb{R}^{n}$ sebarang. Perhatikan bahwa

$$
\begin{aligned}
\|\varphi(x)-\varphi(y)\| & =\sqrt{\langle(\varphi(x)-\varphi(y)),(\varphi(x)-\varphi(y))\rangle} \\
& =\sqrt{\langle\varphi(x), \varphi(x)\rangle-2(\langle\varphi(x), \varphi(y)\rangle)+\langle\varphi(y), \varphi(y)\rangle} \\
& =\sqrt{\langle x, x\rangle-2(\langle x, y\rangle)+\langle y, y\rangle}=\|x-y\| .
\end{aligned}
$$

Terbukti bahwa sebarang pemetaan ortogonal adalah isometri.

\subsection{Metrik Riemannian}

Definisi 3.4. [2] Suatu metrik Riemannian pada manifold smooth $M$ adalah korespondensi yang mengaitkan setiap titik $p \in M$ dengan hasilkali dalam (yang simetri, bilinier, dan definit positif) pada ruang singgung $T_{p} M$. Manifold smooth $M$ yang dilengkapi dengan metrik Riemannian disebut manifold Riemannian.

Misalkan $g$ adalah suatu metrik Riemannian pada $M$ maka untuk setiap $p \in M$, $g_{p}$ adalah suatu hasilkali dalam pada setiap ruang singgung $T_{p} M$ dan $(M, g)$ adalah suatu manifold Riemannian. Misalkan $v, w \in T_{p} M$ dimana $v=\left(v^{1}, \cdots, v^{n}\right)$ dan $w=\left(w^{1}, \cdots, w^{n}\right)$, maka metrik Riemannian dapat ditulis

$$
g_{p}(v, w)=\sum_{i, j=1}^{n} g_{i j}(p) v^{i} w^{j}
$$

dimana $g_{i j}(p)=\left\langle\frac{\partial}{\partial x^{i}}, \frac{\partial}{\partial x^{j}}\right\rangle$. Suatu norm pada suatu ruang singgung $T_{p} M$ didefinisikan oleh

$$
\|v\|=\sqrt{g_{p}(v, v)}
$$

dimana $v \in T_{p} M .[3]$

Contoh 3.5. [2] Suatu manifold smooth $\mathbb{R}^{n}$ adalah suatu manifold Riemannian dengan metrik Riemannian $g$ yang didefinisikan

$$
g_{p}(v, w)=\sum_{i, j=1}^{n} \delta_{i j} v^{i} w^{j}=\sum_{i, j=1}^{n} v^{i} w^{j}=\langle v, w\rangle
$$

untuk setiap vektor $v, w \in T_{p} \mathbb{R}^{n}$, dengan $g_{i j}=\delta_{i j}=\left\langle e_{i}, e_{j}\right\rangle, e_{i}$ suatu basis di $\mathbb{R}^{n}$ dimana $\delta_{i j}$ adalah delta Kronecker bernilai 1 jika $i=j$ dan bernilai 0 jika $i \neq j$ untuk setiap $i, j=1, \cdots, n$.

Teorema 3.6. [2] Setiap smooth manifold $M$ memiliki metrik Riemannian.

Bukti. Misalkan $M$ suatu manifold smooth. Misalkan $\left\{f_{\alpha}\right\}$ menjadi suatu partisi smooth dari subordinate kesatuan pada $M$ untuk menyelimuti $\left\{V_{\alpha}\right\}$ dengan koordinat lingkungan. Ini berarti bahwa $V_{\alpha}$ adalah suatu selimut yang terbatas secara lokal dan $\left\{f_{\alpha}\right\}$ adalah keluarga dari fungsi smooth pada $M$ yang memenuhi $f_{\alpha} \geq 0$ dan $\sum_{\alpha} f_{\alpha}(p)=1$ untuk semua $p \in M, \alpha \in A$. Oleh karena itu, dapat didefinisikan suatu metrik Riemannian pada setiap $V_{\alpha}$ yaitu

$$
g_{p}(u, v):=\sum_{\alpha} f_{\alpha}(p) g_{p}^{\alpha}(u, v)
$$


untuk setiap $p \in M, u, v \in T_{p} M$. Metrik Riemannian pada $V_{\alpha}$ adalah metrik yang diinduksi oleh sistem dari koordinat lingkungan. Jelas bahwa metrik Riemannian yang didefinisikan pada persamaan (3.5) definit positif, simetri dan bilinier. Oleh karena itu, terbukti bahwa sebarang manifold smooth memiliki metrik Riemannian.

Definisi 3.7. [5] Misalkan $(M, g)$ adalah suatu manifold Riemannian.

Jika $\gamma:[a, b] \longrightarrow M$ adalah suatu segmen kurva smooth maka panjang dari $\gamma$ didefinisikan

$$
L_{g}(\gamma):=\int_{a}^{b}\left\|\gamma^{\prime}(t)\right\| d t
$$

dan jarak antara dua titik $p, q \in M$ didefinisikan sebagai

$$
d_{g}(p, q):=\inf \left\{L_{g}(\gamma), \gamma:[a, b] \longrightarrow M: \gamma(a)=p, \gamma(b)=q\right\}
$$

Proposisi 3.8. [5] Misalkan $(M, g)$ suatu manifold Riemannian dan diberikan $\gamma:[a, b] \longrightarrow M$ sebagai suatu bagian kurva smooth. Jika $\tilde{\gamma}$ adalah reparameterisasi $\operatorname{dari} \gamma \operatorname{maka} L_{g}(\tilde{\gamma})=L_{g}(\gamma)$.

Bukti. Misalkan $\gamma$ suatu bagian kurva smooth. Asumsikan $\tilde{\gamma}$ suatu reparameterisasi positif dengan $\varphi:[c, d] \longrightarrow[a, b], \varphi^{\prime}(r)>0$ untuk semua $r \in[c, d]$, diperoleh

$$
\begin{aligned}
L_{g}(\tilde{\gamma}) & =\int_{a}^{b}\left\|\tilde{\gamma}^{\prime}(t)\right\| d t=\int_{c}^{d}\left\|\gamma^{\prime}(\varphi(r)) \varphi^{\prime}(r)\right\| d r=\int_{c}^{d}\left\|\gamma^{\prime}(\varphi(r))\right\| \varphi^{\prime}(r) d r \\
& =\int_{a}^{b}\left\|\gamma^{\prime}(r)\right\| d r=L_{g}(\gamma) .
\end{aligned}
$$

Jadi terbukti bahwa jika $\tilde{\gamma}$ adalah reparameterisasi dari $\gamma$ maka $L_{g}(\tilde{\gamma})=L_{g}(\gamma)$

Proposisi 3.9. [3] Misalkan $d_{g}(p, q)$ untuk semua $p, q \in M$ didefinisikan pada persamaan (3.8), $d_{g}$ disebut fungsi jarak apabila memenuhi:

(1) $d_{g}(p, q) \geq 0$ dan $d_{g}(p, q)>0$ untuk semua $p \neq q$

(2) $d_{g}(p, q)=d_{g}(q, p)$, untuk semua $p, q \in M$

(3) $d_{g}(p, q)+d_{g}(q, r) \geq d_{g}(p, r), \forall p, q, r \in M$.

Selanjutnya dapat dikatakan sebarang manifold Riemannian $(M, g)$ adalah ruang metrik dinotasikan dengan $\left(M, d_{g}\right)$.

Bukti. Misalkan $(M, g)$ suatu manifold Riemannian.

(1) Jelas bahwa $d_{g}(p, q) \geq 0$ untuk semua $p, q \in M$. Misalkan $(U, \varphi)$ dengan $\varphi: U \subset M \longrightarrow \mathbb{R}^{n}$ adalah suatu chart pada smooth manifold $M$ dimana $\left(x^{1}, \cdots, x^{n}\right)$ suatu koordinat lokal di $\mathbb{R}^{n}$. Misalkan $\varphi(p)=0 \in \mathbb{R}^{n}$ dan $\bar{B}_{a}(0)$ adalah suatu bola tutup di $\mathbb{R}^{n}$ dengan $\bar{B}_{a}(0) \subset \varphi(U)$. Asumsikan $\|x\| \leq r$ untuk suatu $r \in \mathbb{R}$ dan $\left(\alpha^{1}, \cdots, \alpha^{n}\right)$ dengan $\sum_{i, j=1}^{n}\left(\alpha^{i}\right)^{2}=1$, maka $\sum_{i, j=1}^{n} g_{i j}(x) \alpha^{i} \alpha^{j}$ mengasumsikan suatu nilai maksimum $K_{r}>0$ dan nilai minimum $k_{r}>0$. Jika $\mathrm{k}, \mathrm{K}$ suatu minimum dan maksimum pada $r=a$, maka

$$
0<k \leq k_{r} \leq\left(\sum_{i, j=1}^{n} g_{i j}(x) \alpha^{i} \alpha^{j}\right)^{\frac{1}{2}} \leq K_{r} \leq K
$$


Jika $\left(\beta^{1}, \cdots, \beta^{n}\right)$ sebarang bilangan riil sedemikian sehingga $\left(\sum_{i, j=1}^{n}\left(\beta^{i}\right)^{2}\right)^{\frac{1}{2}}=$ $b \neq 0$, ganti $\alpha^{i}=\beta^{i} / b$ sehingga

$$
0<k b \leq k_{r} b \leq\left(\sum_{i, j=1}^{n} g_{i j}(x) \beta^{i} \beta^{j}\right)^{\frac{1}{2}} \leq K_{r} b \leq K b
$$

Jika diasumsikan untuk $p, q \in \mathbb{R}^{n}$ dengan $p \neq q$, maka ketaksamaan (3.11) menjadi

$$
0<k\|\varphi(q)\|<k_{r}\|\varphi(q)\| \leq L_{g} \leq K_{r} \int_{a}^{b}\left(\sum_{i=1}^{n}\left(\dot{x}^{i}(t)\right)^{2}\right)^{\frac{1}{2}} d t \leq K \int_{a}^{b}\left(\sum_{i=1}^{n}\left(\dot{x}^{i}(t)\right)^{2}\right)^{\frac{1}{2}} d t
$$

Misalkan $q^{\prime} \in M$ sebarang, dengan $p \neq q^{\prime}$ dan $q^{\prime} \notin \varphi^{-1}\left(\bar{B}_{a}(0)\right) \subset U$.

Misalkan $\gamma(t)$ dengan $0 \leq t \leq c$ adalah suatu kurva smooth dengan $\gamma(0)=$ $p$ dan $\gamma(c)=q^{\prime}$, dan misalkan panjang $\gamma(t)=L_{g}^{\prime}$. Pada kurva smooth $\gamma$ : $[a, b] \longrightarrow M$, untuk $0 \leq t \leq b, \gamma(t)$ termuat didalam lingkungan $\varphi^{-1}\left(\bar{B}_{a}(0)\right)$. Misalkan $\|\varphi(q)\|=r$. Jika $L_{g}$ adalah panjang dari $\gamma(t)$ untuk $0 \leq t \leq b$, maka $L_{g}^{\prime} \geq L_{g}>k r>0$. Karena $L_{g}>0$, maka infimum dari $L_{g}>0$ atau $d_{g}(p, q)>0$ untuk semua $p, q \in M$ dengan $p \neq q$.

(2) Karna pada Proposisi 3.8 disebutkan bahwa panjang suatu reparameterisasi dari $\gamma(t)$ sama dengan panjang $\gamma$, akibatnya $d_{g}(p, q)=d_{g}(q, p)$

(3) Misalkan $\gamma_{1}$ adalah bagian kurva smooth dari $p$ ke $q$ dan $\gamma_{2}$ adalah bagian kurva smooth dari $q$ ke $r$. Misalkan $\gamma$ adalah bagian kurva smooth dari $p$ ke $r$ maka

$$
d_{g}(p, r) \leq L_{g}(\gamma)=L_{g}\left(\gamma_{1}\right)+L_{g}\left(\gamma_{2}\right) .
$$

Ambil infimum dari $L_{g}\left(\gamma_{1}\right)$ dan $L_{g}\left(\gamma_{2}\right)$ sehingga diperoleh

$$
d_{g}(p, r) \leq d_{g}(p, q)+d_{g}(q, r)
$$

Karena ketiga sifat-sifat terpenuhi maka terbukti bahwa sebarang manifold Riemannian adalah ruang metrik.

\section{KESIMPULAN}

Suatu manifold smooth $M$ yang dilengkapi dengan metrik Riemannian disebut manifold Riemannian $(M, g)$. Setiap manifold smooth $M$ memiliki metrik Riemannian. Sebarang manifold Riemannian $(M, g)$ adalah ruang metrik $\left(M, d_{g}\right)$ dengan $d_{g}$ suatu fungsi jarak pada manifold Riemannian.

\section{UCAPAN TERIMA KASIH}

Ucapan terima kasih disampaikan kepadaDr. Admi Nazra, Dr. Shelvi Ekariani dan Monika Rianti Helmi, M.Si yang telah memberi masukan dan saran sehingga penelitian ini dapat terselesaikan.

\section{Daftar Pustaka}

[1] Anton, Howard dan Chris Rorres. 2004. Aljabar Linier Elementer Edisi Kedelapan. Penerbit Erlangga. Jakarta 
148 Riri Alfakhriati dkk.

[2] Carmo, Manfredo Perdiãgo do. 1992. Riemannian Geometry. Birkhäuser, Boston.

[3] Jost, Jürgen. 1995 Riemannian Geometry and Geometric Analysis. Fifth Edition. Springer, Berlin.

[4] Lee, John M. 2010. Introduction to Topological Manifold. Second Edition. Springer, New York.

[5] Lee, John M. 2013. Introduction to Smooth Manifold. Second Edition. Springer, New York.

[6] Pranoto, Iwan. 2004. Pengenalan Geometri Diferensial. Penerbit ITB, Bandung. 